\title{
Impact of Lentiviral Vector-Mediated Transduction on the Tightness of a Polarized Model of Airway Epithelium and Effect of Cationic Polymer Polyethylenimine
}

\author{
Stefano Castellani, Sante Di Gioia, Teresa Trotta, Angela Bruna Maffione, \\ and Massimo Conese \\ Department of Biomedical Sciences, University of Foggia, 71122 Foggia, Italy \\ Correspondence should be addressed to Massimo Conese, m.conese@unifg.it
}

Received 24 December 2009; Revised 31 March 2010; Accepted 9 May 2010

Academic Editor: Karl Chai

Copyright (C) 2010 Stefano Castellani et al. This is an open access article distributed under the Creative Commons Attribution License, which permits unrestricted use, distribution, and reproduction in any medium, provided the original work is properly cited.

\begin{abstract}
Lentiviral (LV) vectors are promising agents for efficient and long-lasting gene transfer into the lung and for gene therapy of genetically determined pulmonary diseases, such as cystic fibrosis, however, they have not been evaluated for cytotoxicity and impact on the tightness of the airway epithelium. In this study, we evaluated the transduction efficiency of a last-generation LV vector bearing Green Fluorescent Protein (GFP) gene as well as cytotoxicity and tight junction (TJ) integrity in a polarized model of airway epithelial cells. High multiplicities of infection (MOI) showed to be cytotoxic, as assessed by increase in propidium iodide staining and decrease in cell viability, and harmful for the epithelial tightness, as demonstrated by the decrease of transepithelial resistance (TER) and delocalization of occludin from the TJs. To increase LV efficiency at low LV:cell ratio, we employed noncovalent association with the polycation branched $25 \mathrm{kDa}$ polyethylenimine (PEI). Transduction of cells with $\mathrm{PEI} / \mathrm{LV}$ particles resulted in 2.5-3.6-fold increase of percentage of GFP-positive cells only at the highest PEI:LV ratios $\left(1 \times 10^{7} \mathrm{PEI}\right.$ molecules/transducing units with $50 \mathrm{MOI} \mathrm{LV)} \mathrm{as} \mathrm{compared} \mathrm{to} \mathrm{plain} \mathrm{LV.} \mathrm{At} \mathrm{this} \mathrm{dose} \mathrm{PEI/LV} \mathrm{transduction} \mathrm{resulted} \mathrm{in} 6.5 \pm 2.4 \%$ of propidium iodide-positive cells. On the other hand, PEI/LV particles did not determine any alteration of TER and occludin localization. We conclude that PEI may be useful for improving the efficiency of gene transfer mediated by LV vectors in airway epithelial cells, in the absence of high acute cytotoxicity and alteration in epithelial tightness.
\end{abstract}

\section{Introduction}

Lentiviral (LV) vectors, such as those derived from HIV1 , show exceptional promise as gene transfer agents and have been proven to be effective vehicles for transduction of epithelial cells of various organs, including airway epithelial cells in the lung [1]. The epithelium lining the bronchi/bronchioli is the target cell compartment for a therapeutic approach based on gene delivery in cystic fibrosis (CF), a chronic autosomal recessive disorder due to mutation in the CF Transmembrane Conductance Regulator (CFTR) gene [2]. LV vectors bear some fundamental characteristics which could be useful for treating the CF lung disease, such as: (1) they integrate into the host genome and determine a long-term expression of either marker or CFTR gene in animal and human xenograft models [3-7]; (2) they can be repeatedly administered without loss of efficiency [8]; and (3) they do not elicit a gross inflammatory response in vitro [9] and in vivo $[4,10]$.

The mechanism(s) of viral vector interaction with the apical plasma membrane and internalization has been an intensely studied question, in particular for adenoviral and adeno-associated viral vectors [11-16]. The expression of receptors for these viral vectors and oncoretroviruses is more abundant on the basolateral membrane than on the apical side of the respiratory epithelium and they are hardly accessible because of the airway tight junctions $[12,17,18]$. HIV-1-derived LV vectors expressing vesicular stomatitis virus G glycoprotein (VSV-G) on their capsid have been shown previously to transduce a polarized airway 
epithelium only in the presence of preconditioning agents with disruptive, although transient, effects on tight junctions $[4,5,19]$. These studies indicated entry block due to absence or low numbers of VSV-G receptors on the apical membrane of the airway epithelium, as it has been identified for other viral vectors, or postentry block, concerning the endocytosis route and nuclear import of viral genomes. $\mathrm{LV}$ vectors have not been investigated in so much detail in respect to their attachment to and internalization by the cells. Building on the previoulsy published work by Guibinga et al. [20], we observed that glycosaminoglycans (GAGs) are involved in LV vector-mediated transduction of polarized airway epithelial cells [21]. In that study, a good transduction efficiency of polarized cellular monostrates with a last-generation LV vector pseudotyped with VSV-G was obtained, but only at high virus to cell ratios. Given that no studies have tested directly the effect of LV vectors on the tight junction (TJ) stability and organization in airway epithelial cells, we evaluated the transduction efficiency as well as acute cytotoxicity, transepithelial resistance (TER), and occludin localization at the TJ level in a bronchialderived cell line grown in polarized fashion. We find that the VSV-G-pseudotyped LV vector infection at high viral loads is cytotoxic and determines occludin loss from the apical plasmamembrane and reduction of TER. In order to rule out the toxic effect of LV particles, we used LV virions noncovalently complexed with a cationic vector (i.e. polyethylenimine).

\section{Materials and Methods}

2.1. Lentiviral Vector Production. The VSV-G pseudotyped LV vector stock was prepared as previously described $[21,22]$. Briefly, the lentivirus-based gene delivery system comprises four components: (1) the packaging plasmid pMDLg/pRRE, which contains elements such as structural proteins and enzymes involved in the formation of the viral particles, derived from the gag-pol genes; (2) the pRSVREV plasmid, which contains posttranscriptional regulator for gag and pol expression, as well as nuclear RNA export encoded by the rev gene; (3) the transfer vector pRRLsin18.cPPT.CMV.eGFP.Wpre carrying the transgene GFP with the insertion of the PPT and the woodchuck post-transcriptional regulatory element (WPRE); and (4) the pMD2.G plasmid containing the heterologous glycoprotein VSV-G. Cotransfection of the four plasmid vectors was performed on $293 \mathrm{~T}$ cells by calcium phosphate precipitation. The supernatant containing LV particles was concentrated by two rounds of ultracentrifugation and assayed for p24 Gag antigen by enzyme-linked immunosorbent assay. The viral titer was determined by HeLa cell infection and subsequent flow cytometry analysis. The yield of the concentrated virus was typically $10^{9}$ transducing units (TU)/ml and the specific activity ranged between 1.56 and $4.17 \times 10^{5} \mathrm{TU} / \mathrm{ng}$ of $\mathrm{p} 24$.

2.2. Polarization of Bronchial Epithelial Cells. 16HBE41ocells, derived from human bronchial epithelium (a kind gift of Professor D. Gruenert, University of California at San
Francisco, CA, USA), were grown in MEM supplemented with Earle's salt, $10 \%$ fetal bovine serum, L-glutamine and penicillin/streptomycin. They were routinely grown on plastic flasks coated with an extracellular matrix containing fibronectin/vitrogen/bovine serum albumin. The extracellular matrix coating is prepared in the laboratory as follows: $10 \mu \mathrm{g} / \mathrm{ml}$ Fibronectin (BD Biosciences, CA, USA), $100 \mu \mathrm{g} / \mathrm{ml}$ albumin from bovine serum (Sigma-Aldrich, Milan, Italy), and $30 \mu \mathrm{g} / \mathrm{ml}$ bovine collagen type I (BD Biosciences) are dissolved in MEM. The mixture is sterilized by $0.2 \mu \mathrm{m}$ filter. To induce polarization, cells were seeded on $6.5-\mathrm{mm}$ diameter Snapwell, $0.4-\mu \mathrm{m}$ pore size (Corning, Acton, MA, USA) at $1 \times 10^{5}$ per filter coated with the same extracellular matrix. Under these conditions, cells grow as a polarized sheet of cells and develop a transepithelial resistance of 550 $\mathrm{Ohm} \times \mathrm{cm}^{2}$ on average, as measured by a voltohmmeter (Millicell-ERS; Millipore, Vimodrone, Italy).

2.3. Transduction of Polarized Monolayers. Polarized cells were incubated with the LV-GFP vector at different multiplicities of infection (MOI) for 4 or 24 hours and then either immediately studied for propidium iodide staining and cell viability or incubated for further 48 hours for evaluation of GFP expression. MOI refers to the number of TU per one cell. Because we seeded $1 \times 10^{5}$ cells per well, a MOI of 10 is equivalent to $10^{6} \mathrm{TU}$; and a MOI of 100 refers to $10^{7} \mathrm{TU}$, and so forth.

Branched polyethylenimine (MW 25,000 Da) was obtained from Sigma as $50 \% \mathrm{w} / \mathrm{v}$ solution. The solution was titrated with $\mathrm{HCl}$ solution to a $\mathrm{pH}$ of 7.4 and used as a $4.5 \mathrm{mg} / \mathrm{ml}$ stock solution $(100 \mathrm{mM}$; stoichiometrically, this solution corresponds to $10.8 \times 10^{13}$ molecules of PEI per $\mu \mathrm{l}$ of solution). Ten $\mu$ l of saline containing different amounts of PEI stock solution were added to $10 \mu \mathrm{l}$ of saline containing 50 MOI $\left(5 \times 10^{6} \mathrm{TU}\right)$ of $\mathrm{LV}$ in order to obtain PEI molecules/TU ratios ranging from $5 \times 10^{4}$ to $1 \times 10^{7}$ (corresponding to a range of $0.0625-12.5 \mu \mathrm{g} / \mu \mathrm{l}$ as final concentration of PEI). Spermidine (Sigma-Aldrich) stock solution ( $1 \mathrm{M})$ was diluted in order to obtain a final concentration ranging from $0.08 \mu \mathrm{M}$ to $8 \mathrm{mM}$ (corresponding to spermidine molecules/TU ratios ranging from $1 \times 10^{6}$ to $1 \times 10^{11}$ ). The suspension containing either PEI/LV or spermidine/LV was incubated for 15 minutes at room temperature and then added to cells. In another experimental setting, cells were preincubated with spermidine (final concentration ranging from $0.08 \mathrm{mM}$ to $8 \mathrm{mM}$ ) for 1.5 hours, washed, and then infected with $\mathrm{PEI} / \mathrm{LV}$ at the ratio of $1 \times 10^{7}$ with $50 \mathrm{MOI}$ LV. The medium was changed 24 hours later and after further 48 hours, a preliminary evaluation of GFP expression was carried out by epifluorescence and confocal microscopy (see below). Analysis of GFP production by flow cytometry was performed as follows. The cells were washed twice with phosphate-buffered saline (PBS), harvested by digesting with trypsin/ethylenediaminetetracetic acid (EDTA), and fixed in $2 \%$ paraformaldehyde. The cells were analyzed by fluorescence-activated cell sorting (FACS) with a EPICS XL MCL flow cytometer (Beckman Coulter Fullerton, CA, USA). The percentage of GFP-positive cells was determined after setting the gating on $99 \%$ of an untransfected control 


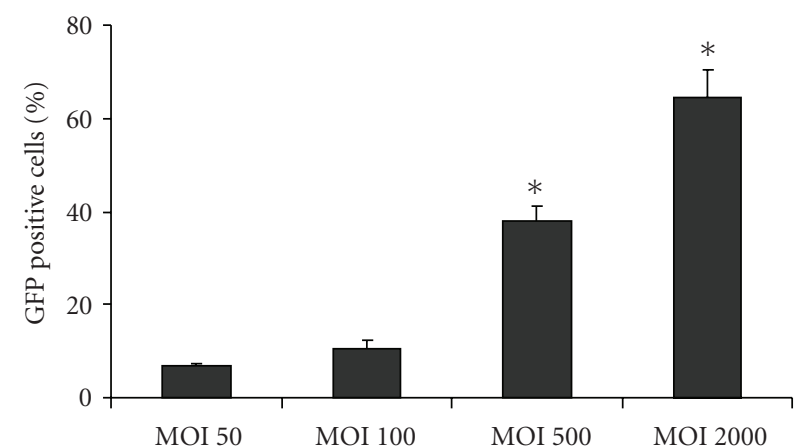

(a)

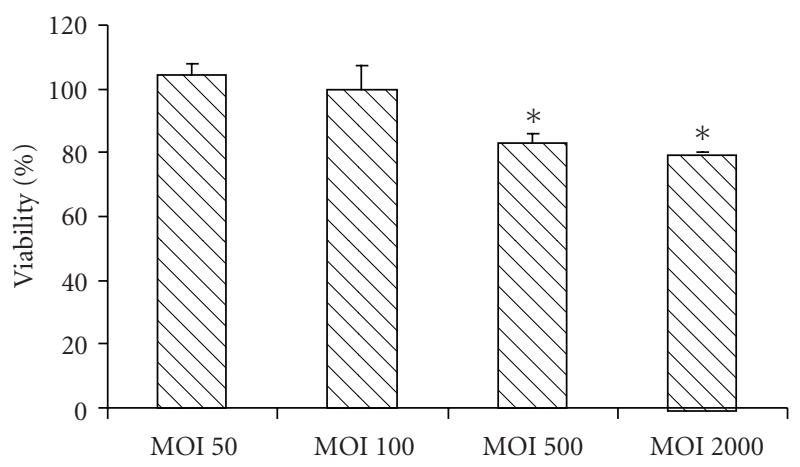

(c)

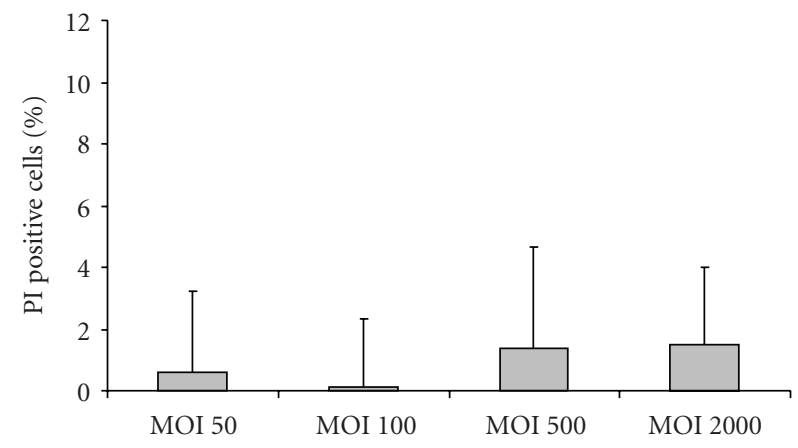

(e)

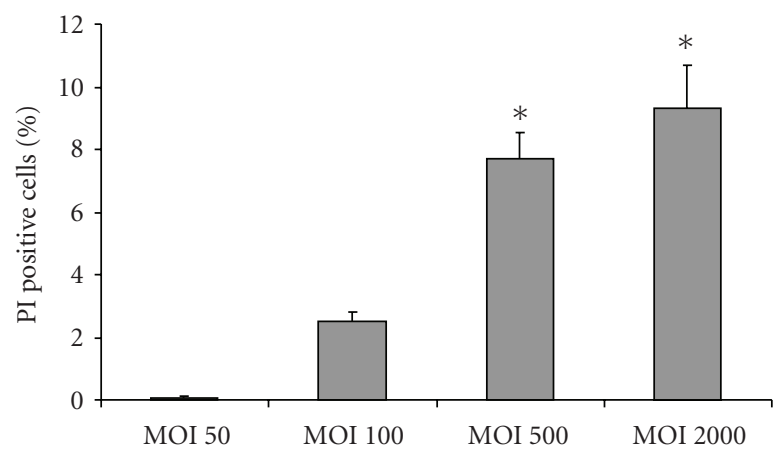

(b)

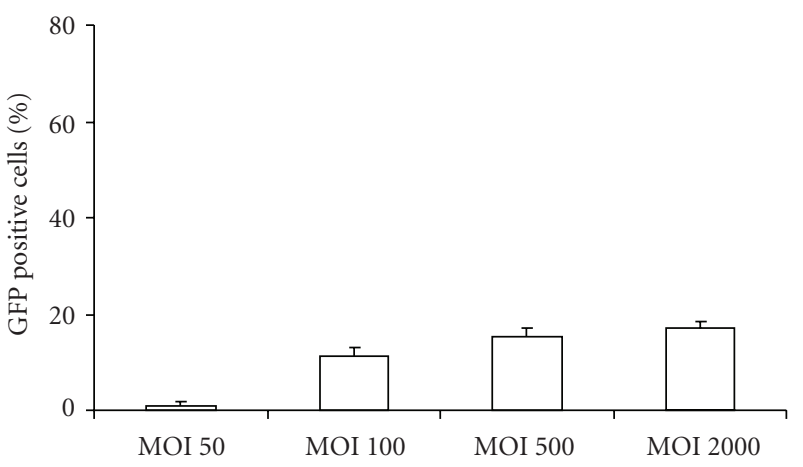

(d)

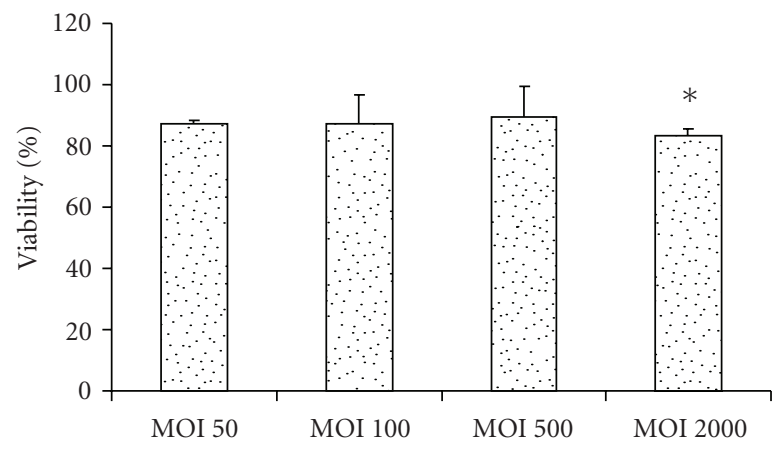

(f)

FIgure 1: Efficiency and cytotoxicity of LV transduction. Polarized 16HBE41o- cells were incubated with different MOIs for 24 (a, b, and c) or $4(\mathrm{~d}, \mathrm{e}$, and $\mathrm{f}$ ) hours and then analyzed either immediately for membrane permeability (b and e) and viability (c and f) or incubated for further 48 hours and evaluated for GFP expression (a and d). Percentage of propidium iodide (PI)-positive cells incubated with medium only was $3.45 \pm 0.28 \%$ and subtracted from the other values. In the viability assay, untreated cells were incubated with medium only and considered as 100\%. Data are expressed as means \pm SD of two-three experiments. A and B: ${ }^{*} P<.05$ for 500 and 2000 MOIs versus 50 and 100 MOIs. C and F: ${ }^{*} P<.05$ for 500 and 2000 MOIs versus mock.

population of cells and by subtracting the fluorescence of the untransfected control cells. Ten thousand cells were examined in each experiment. Analysis of GFP production was performed by plotting the FLH-1 channel $(512-537 \mathrm{~nm}$, with peak at $525 \mathrm{~nm}$ ) against the FLH-3 channel (608$632 \mathrm{~nm}$, with peak at $620 \mathrm{~nm}$ ).

2.4. Propidium Iodide Staining. Propidium iodide is an effective stain to identify nonviable cells since the dye is excluded by intact cell membranes and passes through damaged cell membranes and intercalates with DNA and RNA to form a bright red fluorescent complex $[23,24]$. Briefly, cells on transwells were incubated with $25 \mu \mathrm{g} / \mathrm{ml}$ propidium iodide (Sigma-Aldrich) for 20 minutes on ice, were washed with PBS, harvested by digesting with trypsin/EDTA, and resuspended in PBS. In each experiment, as a toxicity control, cells were incubated with $0.1 \%$ Triton X-100 (Sigma-Aldrich) for 5 minutes at room temperature. This treatment resulted in $44 \%$ of propidium iodide-positive cells on average. After various treatments, cells were analysed by FACS. The percentage of propidium iodide positive cells was determined after setting the gating on $99 \%$ of an untreated control population of cells and by subtracting the fluorescence of untreated control cells. Ten thousand cells were examined 


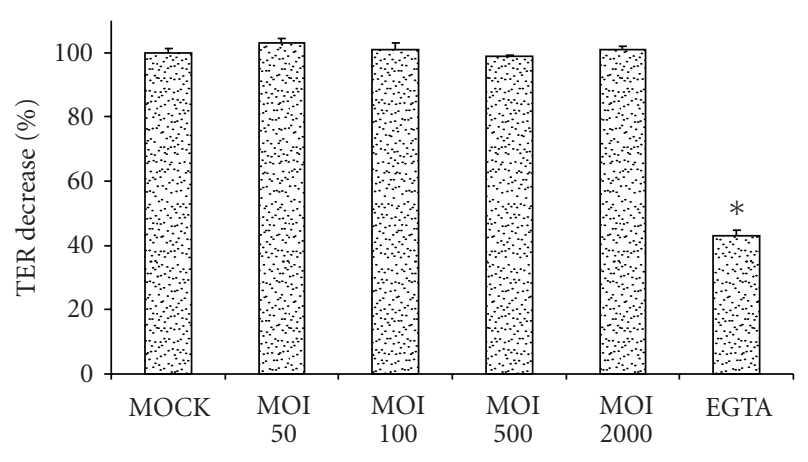

(a)

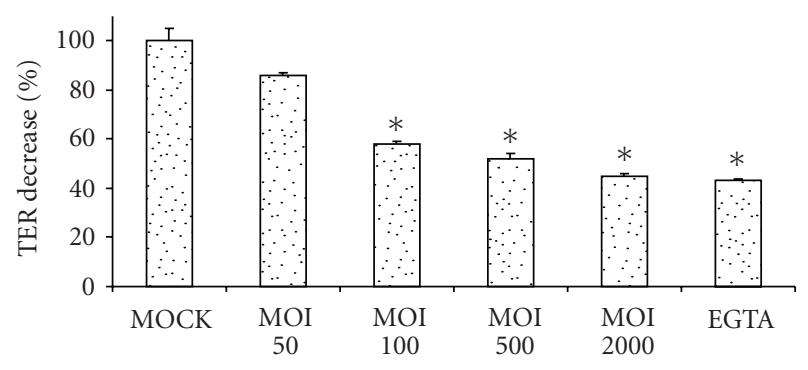

(b)

Figure 2: Effect of LV transduction on TER. Polarized 16HBE41ocells were incubated with different MOIs and, 4 or 24 hours later, TER was measured. Mock is represented by cells incubated with medium only. As a positive control, cells were incubated with 12 mM EGTA for 30 minutes. TER values are shown as \% of mock cells that were $523 \pm 44 \mathrm{Ohm} \times \mathrm{cm}^{2}$. Data are expressed as means $\pm \mathrm{SD}$ of three experiments. A: ${ }^{*} P<.05$ for EGTA versus mock. B: ${ }^{*} P<.05$ for EGTA, 100, 500, and 2000 MOIs versus mock.

in each experiment. Analysis of propidium iodide positive cells was performed by plotting the red channel (FLH-2; 562$588 \mathrm{~nm}$, with peak at $575 \mathrm{~nm}$ ) against the FLH-1 channel.

2.5. MTT Assay. MTT (3-(4,5-dimethyl-thiazol-2-yl)-2,5diphenyl tetrazolium bromide) is a water-soluble yellow dye that is readily taken up by viable cells and reduced by the action of mitochondrial dehydrogenases. The reduction product is a water-insoluble blue formazan, that must then be dissolved for colorimetric measurement. Briefly, a stock solution of MTT (Sigma-Aldrich) in phosphate buffered saline (PBS) $(5 \mathrm{mg} / \mathrm{ml})$ was added to the upper compartment of each well reaching a final concentration of $0.5 \mathrm{mg} / \mathrm{ml}$ (in $200 \mu \mathrm{l}$ of complete medium). After 4 hours the formazan crystals were dissolved in a $10 \%$ SDS $/ 50 \%$ dimethyl-formamide solution, and $100 \mu \mathrm{l}$ of the solution were transferred in a 96-well plate and measured spectrophotometrically by an ELISA reader (PowerWave HT, Bio-tek, Milan, Italy) at a wavelenght of $570 \mathrm{~nm}$ with a reference wavelenght of $690 \mathrm{~nm}$. The relative viability was calculated in respect to untreated cells (considered as 100\%).

2.6. RT-PCR. Peripheral blood mononuclear cells (PBMCs) were isolated from the whole blood of three normal donors using Lymphoprep (Axis-Shield, Oslo, Norway), according to the published protocol [25], and pooled. Total RNA was extracted from polarized 16HBE140- cells and PBMCs using Trizol reagent (Invitrogen, S. Giuliano Milanese, Italy) following the protocol suggested by the manufacturer. The concentration of RNA was estimated by Nanodrop 1000 spectrophotometer (Thermo Scientific, Waltham, MA, USA) at $260 \mathrm{~nm}$ wavelength and the purity was confirmed by measuring the absorbance ratio at 260/280 nm wavelengths. $1 \mu \mathrm{g}$ RNA was used to prepare cDNA by using a RevertAid First Strand cDNA Synthesis Kit (Fermentas, Burlington, Canada). Retrotranscription was performed under the following conditions: incubation for 60 minutes at $37^{\circ} \mathrm{C}$ followed by 5 minutes at $70^{\circ} \mathrm{C}$. RNA were retrotranscripted in the presence of 200 units of RevertAid M-MuLV Reverse Transcriptase, $0.4 \mu \mathrm{M}$ of oligo $(\mathrm{dT})_{18}$ primer, $1 \mathrm{mM}$ of nucleotide mix, 20 units of Ribolock Rnase Inhibitor, and commercial buffer (Fermentas). For the PCR reaction, $100 \mathrm{ng}$ of cDNA were amplified in the presence of 1 unit Taq polymerase (Fermentas), $0.4 \mu \mathrm{M}$ of each primer (Eurofins MWG Operon/M Medical Srl, Milan, Italy), $0.2 \mathrm{mM}$ of nucleotide mix, and commercial buffer containing $2 \mathrm{mM}$ $\mathrm{MgCl}_{2}$ (Fermentas). The primers for occludin amplification were forward 5'AGTGAGTGCTATCCTGGGCAT- 3' and reverse 5'-CCTTTGCAGGTGCTCTTTTTG-3' which produced a DNA segment of $600 \mathrm{bp}$. PCR was performed under the following conditions: initial denaturation for 2 minutes at $94^{\circ} \mathrm{C}$, followed by 25 cycles of denaturation (15 seconds, $\left.94^{\circ} \mathrm{C}\right)$, annealing $\left(30\right.$ seconds, $\left.58^{\circ} \mathrm{C}\right)$ and extension ( 1 minute, $72^{\circ} \mathrm{C}$ ). As control for RNA integrity, we performed the $\beta$-actin PCR reaction using the following primers: forward 5'-CAACTGGGACGACATGGA3' and reverse 5'-ACGTCACACTTCATGATGGA-3', which produced a DNA segment of $610 \mathrm{bp}$. PCR was performed under the following conditions: initial denaturation for 2 minutes at $94^{\circ} \mathrm{C}$, followed by 35 cycles of denaturation ( 15 seconds, $94^{\circ} \mathrm{C}$ ), annealing $\left(30\right.$ seconds, $56^{\circ} \mathrm{C}$ ) and extension ( 1 minute, $72^{\circ} \mathrm{C}$ ). The identity of amplified products was confirmed by determination of molecular size on agarose gel electrophoresis (1.5\% agarose in buffer containing $40 \mathrm{mM}$ Tris/acetate and $1 \mathrm{mM}$ EDTA) and visualized by ethidium bromide staining $(0.5 \mu \mathrm{g} / \mathrm{ml})$ under ultraviolet light.

2.7. Confocal Microscopy. For occludin immunolocalization, polarized $16 \mathrm{HBE} 14 \mathrm{o}-$ cells were washed three times with PBS, fixed in 3\% paraformaldehyde, $2 \%$ sucrose, and permeabilized with ice cold Triton Hepes buffer $(20 \mathrm{mM}$ HEPES, $300 \mathrm{mM}$ sucrose, $50 \mathrm{mM} \mathrm{NaCl}, 3 \mathrm{mM} \mathrm{MgCl} 2,0.5 \%$ Triton $\mathrm{X}-100, \mathrm{pH} 7.4$ ) for 5 minutes at room temperature. Cells were incubated with blocking solution (2\% bovine serum albumin [BSA], 2\% FBS) for 15 minutes at $37{ }^{\circ} \mathrm{C}$, then with fluorescein isothiocyanate (FITC)-conjugated mouse antiOccludin antibody (Zymed Laboratories Inc., San Francisco, CA, USA) (dilution 1 : 100) for 30 minutes at $37^{\circ} \mathrm{C}$. Cells were rinsed three times with $0.2 \%$ BSA. Filters were excised and placed side up on a glass slide, and overlayed with a drop of Fluorescent Mounting Medium (Dako, Milan, Italy) followed by a coverslip. Cells were analyzed using Nikon TE2000 microscope coupled to a Radiance 2100 confocal dual-laser scanning microscopy system (Bio-Rad, Segrate, 


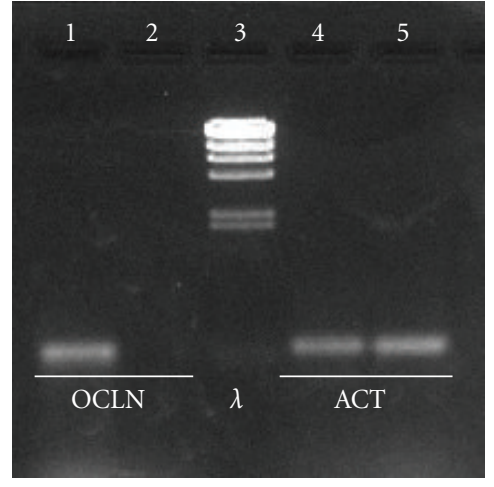

(a)

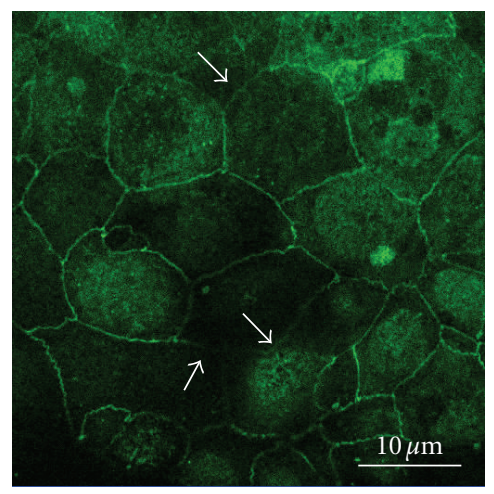

(d)

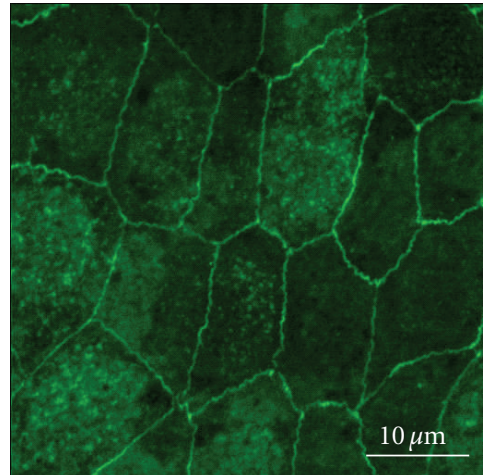

(b)

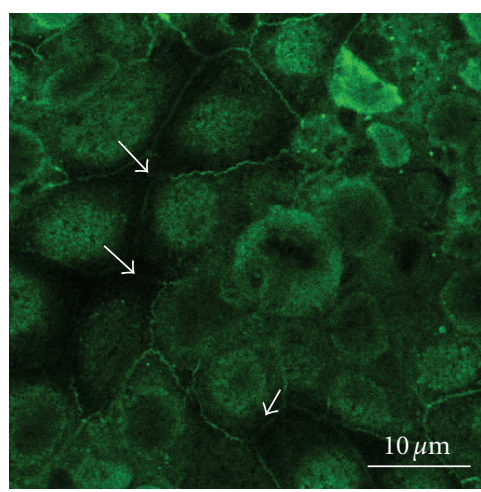

(e)

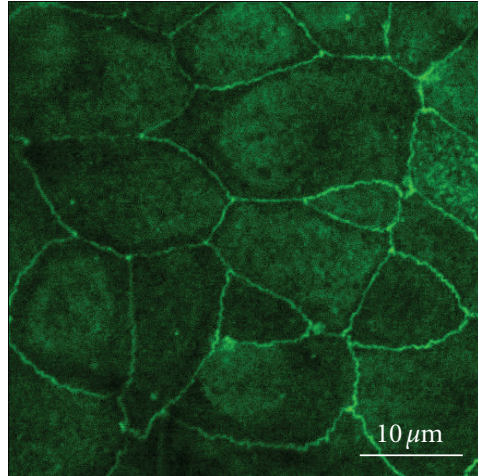

(c)

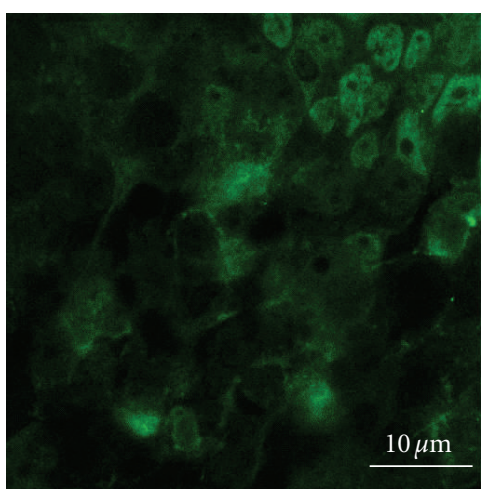

(f)

FIGURE 3: Effect of LV transduction on occludin localization. Expression of occludin mRNA by RT-PCR (a). Note that occludin (OCLN) transcript is detected in 16HBE14o- cells (lane 1) but not in PBMCs (lane 2). $\beta$-actin (ACT) transcripts were detected in 16HBE14o- and PMBCs (lanes 4 and 5, respectively). In lane 3, $\lambda$ HindIII marker. Polarized 16HBE41o- cells were incubated with 50 (C), 500 (D) or 2000 (E) MOIs and, 24 hours later, occludin localization was evaluated by immunofluorescence and confocal microscopy. Controls included mock cells (B) and cells treated with $12 \mathrm{mM}$ EGTA for 30 minutes (F). En-face micrographs are shown. Occludin-specific signal is in green. A peripheral chicken-wire pattern of occludin localization is noted in B and C. In D and E, white arrows point out to lack of occludin staining at cell borders and between cells. In F, occludin staining is lost from cell borders and distributed intracellularly. Note that some intracellular signal is visible also in B-E. Bar: $10 \mu \mathrm{m}$.

Italy). Specimens were viewed through a $60 \mathrm{X}$ oil immersion objective. The microscope was equipped with a FITC filter (excitation $395 \mathrm{~nm}$, emission $509 \mathrm{~nm}$ ). Digital images were processed using the program Laser Sharp 2000 (Bio-Rad).

For GFP detection, cells were fixed and permeabilized, incubated with propidium iodide (diluted at $1: 5,000$ of $1 \mathrm{mg} / \mathrm{ml}$ stock solution) for 5 minutes at $37^{\circ} \mathrm{C}$, and washed. Filters were mounted and observed through the FITC and TRITC (excitation $488 \mathrm{~nm}$, emission $620 \mathrm{~nm}$ ) filters.

2.8. Statistics. Results are presented as means \pm standard deviation (SD) of the means. Statistical significance of differences was evaluated by a two-tailed unpaired Student's $t$-test.

\section{Results}

3.1. Transduction Efficiency and Cytotoxicity of LV Particles. We have previously demonstrated LV-mediated transgene delivery and expression in polarized airway epithelial cells at high LV: cell ratios, necessitating at least 2000 MOI (Multiplicity of Infection) [21]. High MOIs could be toxic to the cells. Thus, we interrogated the transduction efficiency and the cytotoxicity of LV vectors in polarized 16HBE41o- cells. Cells were incubated with different MOIs of LV particles for 24 hours, and then either immediately studied for propidium iodide staining (to assess membrane permeability) and viability (by means of the MTT assay), or incubated for further 48 hours for evaluation of GFP expression. As shown in Figure 1(a), the higher the MOI the higher the percentage of GFP-positive cells. Only cells with altered plasmamembrane permeability will intake propidium iodide which will bind nuclear DNA. The higher the MOI the higher the percentage of propidium iodide-stained cells (Figure 1(b)). The viability was decreased only at MOIs 500 and 2000 (Figure 1(c)).

To investigate acute cytotoxicity of LV particles, membrane permeability and viability were assayed also after incubation of cells with LV particles for 4 hours. At any MOI, LV particles did not exert any direct permeabilizing effect on polarized cells (Figure 1(e)) and decreased the viability 


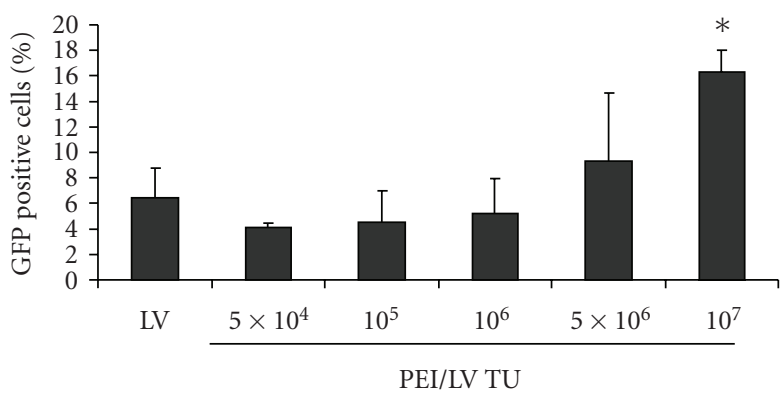

(a)

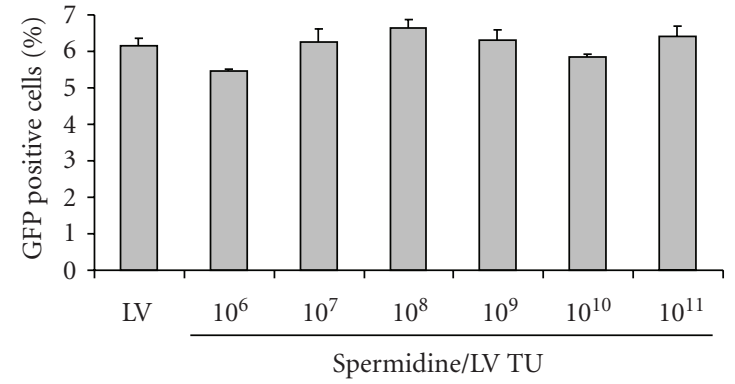

(b)

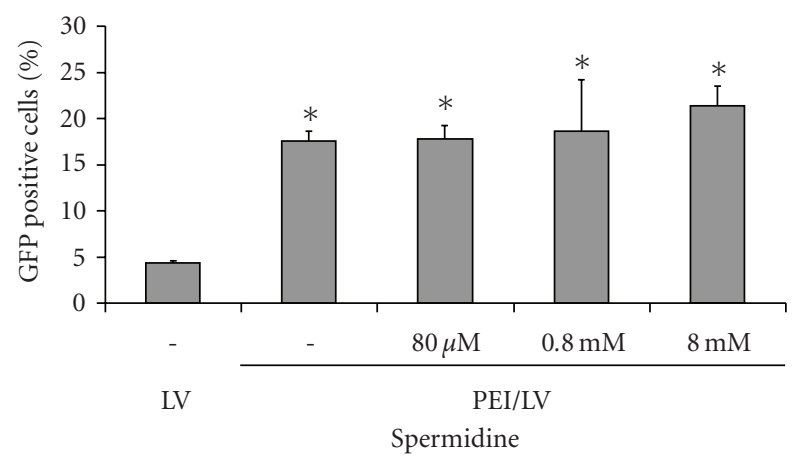

(c)

FIGURe 4: Efficiency and effect on membrane permeability of PEI/LV vectors. Polarized 16HBE41o- cells were incubated with LV (50 MOI) either alone, formulated at different PEI molecules/TU ratios (A), or at different spermidine molecules/TU ratios (B) for 24 hours and then further incubated for 48 hours and evaluated for GFP expression. In another experimental setting, cells were pre-incubated with spermidine (range $0.08-8 \mathrm{mM}$ ) prior to addition of PEI/LV vector formulated at $1 \times 10^{7}$ ratio with $50 \mathrm{MOI} \mathrm{LV}(\mathrm{C})$. Note that PEI/LV increased the transduction efficiency by 3.6 fold as compared to plain LV. Data are expressed as means \pm SD of two-three experiments. A: ${ }^{*} P<.05$ for $10^{7}$ $\mathrm{PEI} / \mathrm{LV}$ TU versus all the other conditions except $5 \times 10^{6}$. C: ${ }^{*} P<.05$ for all the conditions versus LV alone.

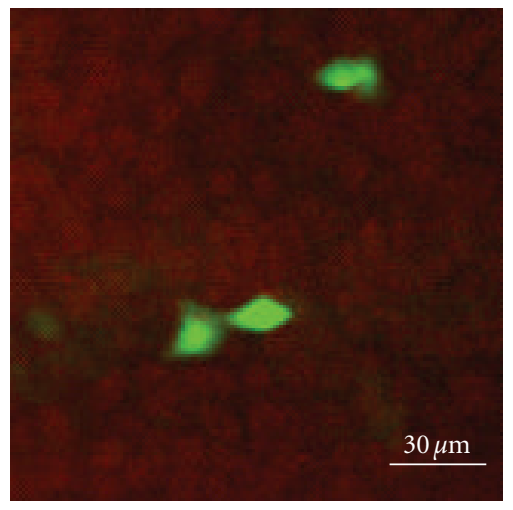

(a)

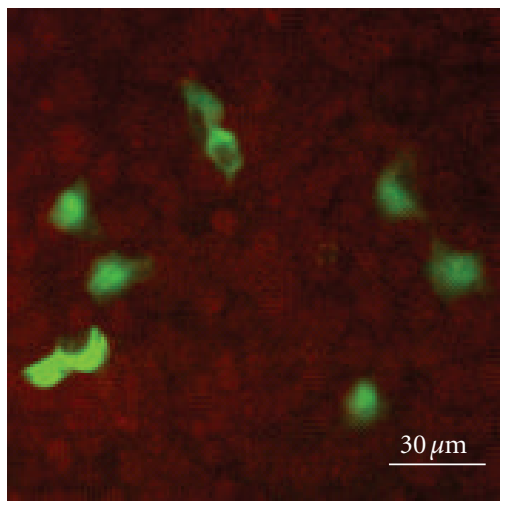

(b)

FIgURE 5: GFP detection by confocal microscopy. Polarized 16HBE41o- cells were incubated with 50 MOI LV (a) or with PEI/LV formulated at $1 \times 10^{7}$ ratio with $50 \mathrm{MOI}$ LV (b). 72 hours later cells were stained with propidium iodide and analyzed by confocal microscopy. GFP-positive cells are in bright green while nuclei are stained in red. Note an approximately 3-fold increase in GFP-positive cells in B as compared to A. En-face micrographs are shown. Bar: $30 \mu \mathrm{m}$.

only at MOI 2000 (Figure 1(f)). Under these conditions, the percentage of transduced cells was lower than in the 24-hour protocol (Figure 1(d)).

These data show a dose-dependent cytotoxic effect of the LV vector, in terms of both alteration of membrane permeability and cell viability.
3.2. Effect of LV Transduction on Transepithelial Resistance and Occludin Localization. Since the LV vector shows a disturbing effect on membrane permeability, the impact of LV particles on the tightness of the epithelial monostrates was initially investigated by measuring transepithelial resistance (TER). TER was decreased in a MOI-dependent 


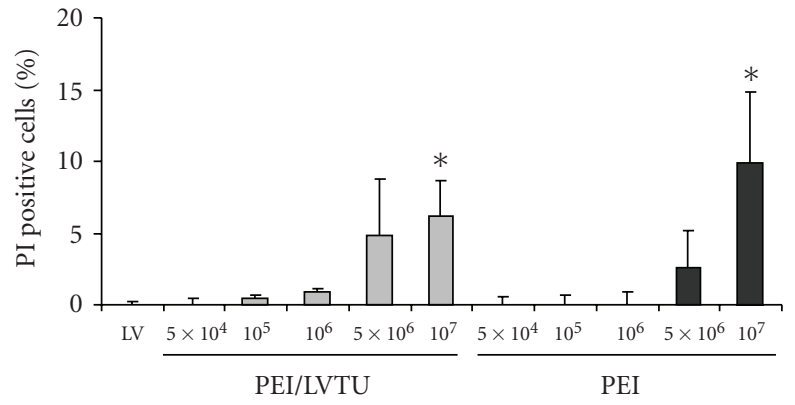

(a)

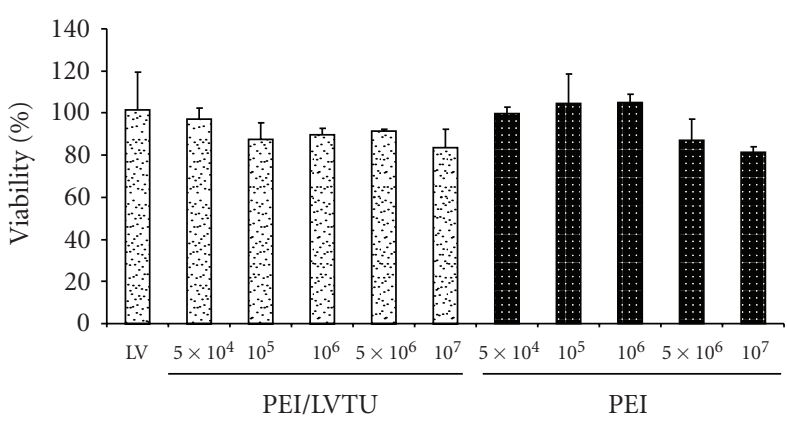

(b)

FIGure 6: Cytotoxicity of PEI/LV vectors. Polarized 16HBE41o- cells were incubated with LV (50 MOI) either alone or formulated at different PEI molecules/TU ratios with 50 MOI LV for 24 hours and then analyzed for propidium iodide staining (a) or MTT assay (b). The same amounts of PEI used in the formation of PEI/LV vectors were tested for their cytotoxicity. Percentage of propidium iodide (PI)-positive cells incubated with medium only was $4.68 \pm 1.8$ and subtracted from the other values. In the viability assay, untreated cells were incubated with medium only and considered as $100 \%$. Data are expressed as means \pm SD of two-three experiments. a: ${ }^{*} P<.05$ for $10^{7} \mathrm{PEI} / \mathrm{LV}$ TU and free PEI versus all the other conditions except $5 \times 10^{6}$.

fashion when cells were incubated with LV vectors for 24 hours (Figure 2(a)), whereas was not affected at 4 hours (Figure 2(b)). The effect observed with 2000 MOI was similar to that achieved by ethylene glycol-bis(2-aminoethyl)$\mathrm{N}, \mathrm{N}, \mathrm{N}^{\prime}, \mathrm{N}^{\prime}$-tetra-acetic acid (EGTA) (Figure 2), a Ca ${ }^{2+}$ chelator known to transiently disrupt epithelial tight junctions [26].

Tight junctions (TJs) are multiprotein complexes composed of integral proteins (claudins, occludin, and JAM [junctional adhesion molecule]) that associate with cytoplasmic plaque proteins ( $\mathrm{ZO}-1, \mathrm{ZO}-2$, and $\mathrm{ZO}-3$ ). The former mediate cell-cell adhesion, while the latter function as a bridge between the TJ and the actin cytoskeleton [27, 28]. Since occludin has been shown to be internalized upon infection with group B coxsackievirus (CVB) [29] and hepatitis C virus (HCV) [30], we chose to study occludin expression and localization in cells infected with the LV vector. Preliminarly we evaluated mRNA occludin expression in 16HBE41o- cells. Reverse transcription-PCR revealed the presence of an occludin specific band (Figure 3(a)). Freshly isolated and unstimulated lymphocytes and monocytes have been shown to not express occludin at the mRNA and protein level [31, 32]. PBMCs obtained from normal donors were negative for occludin mRNA expression (Figure 3(a)), confirming the specificity of the occludin amplification in 16HBE14o- cells.

Polarized 16HBE140- cells were incubated with the LV vector at different MOIs and analyzed by immunofluorescence and confocal microscopy 24 hours postinfection. Untreated cells displayed sharp circumferential organization of occludin at the lateral membrane between neighbouring cells (Figure 3(b)). In EGTA-treated cells, occludin was chaotically distributed within the cytosol (Figure 3(f)). High LV MOIs (500 and 2000) determined discontinuity in the occludin pattern at TJ location (Figures 3(d) and 3(e), with 2000 MOI causing stronger disorganization of TJs. On the other hand, 50 MOI did not cause any alteration in occludin localization at the cell periphery (Figure 3(c)). Taken together, these results show that high-but not low- viral-to-cell ratios determine disruption of TJs when TJs are probed at 24 hours postinfection.

3.3. Effect of PEI and Spermidine on LV-Mediated Transduction. These results prompted us to investigate if LVmediated transduction at low MOI could be enhanced by the polycation polyethylenimine (PEI). Cationic lipids and polymers have been used to increase retrovirus titer and to enhance transduction of target cells [33-36]. Various amounts of branched $25 \mathrm{kDa}$ PEI molecules were mixed with 50 MOI of LV particles to obtain different PEI molecules/TU ratios. Cells were incubated with $\mathrm{LV}$ alone or $\mathrm{PEI} / \mathrm{LV}$ for 24 hours and GFP expression was evaluated 48 hours later by cytofluorimetry. The percentage of transduced cells did not change with low PEI:LV ratios as compared with LV alone, and only the $10^{7}$ ratio produced a significant 2.5fold increase in GFP-positive cells as compared to plain LV (Figure 4(a)). Epifluorescence and confocal microscopy analysis of transduced cells confirmed that PEI increased by approximatively 3 fold the efficiency of LV-mediated transduction, as visualized by the number of GFP-positive cells (Figure 5).

To see whether the enhancing effect of PEI could be universal to polyamines, we sought to determine the effect of native spermidine, a polyamine which is cationic at physiological $\mathrm{pH}$ [37]. A wide range of spermidine molecules/TU ratios was tested (corresponding to a molar concentration range from $0.08 \mu \mathrm{M}$ to $8 \mathrm{mM}$ ), but no effect on the transduction rate given by plain LV particles (used at $50 \mathrm{MOI}$ ) was observed (Figure 4(b)). Thus, the enhancing effect seems to be unique to PEI. In alternative, we investigated whether spermidine could inhibit the PEI/LV-mediated transduction. In this case we used only the highest molar concentrations of spemidine. Preincubation of polarized 16HBE14o- cells with native spermidine $(0.08-8 \mathrm{mM})$ before addition of PEI/LV formulated at the highest ratio $\left(1 \times 10^{7}\right.$ with $\left.50 \mathrm{MOI} \mathrm{LV}\right)$ did not exert any alteration in the efficiency of PEI/LV (Figure 4(c)). In these experiments, the enhancing effect of $\mathrm{PEI} / \mathrm{LV}$ on plain LV was of 3.6 fold. 
3.4. Cytotoxicity of PEI/LV. PEI/LV particles and free PEI were interrogated for their cell toxicity using the propidium iodide staining and the MTT assay. Cells were incubated with vectors for 24 hours, stained with propidium iodide for 30 minutes, and analyzed by cytofluorimetry. As shown in Figure 6(a), only cells incubated with the highest PEI:LV ratios with $50 \mathrm{MOI} \mathrm{LV},\left(10^{7} \mathrm{PEI} / \mathrm{TU}\right)$ showed a significant increase in nuclei stained with propidium iodide (from $0 \%$ up to $6.5 \pm 2.4 \%)$. Intriguingly, the same amount of PEI alone $\left(1 \times 10^{7}\right.$ molecules $)$ caused the uptake of propidium iodide by $9.9 \pm 4.9 \%$ of cells. Figure $6(\mathrm{~b})$ shows that $\mathrm{PEI} / \mathrm{LV}$ and free PEI exerted a small toxic effect on cells at highest doses. These results suggest that the membrane permeabilizing effect of $\mathrm{PEI} / \mathrm{LV}$ vectors could be attributed to free PEI, as previously shown by the toxicity exerted by PEI alone [38].

3.5. Effect of PEI/LV on TER and Occludin Localization. TER was measured at 4 and 24 hours postinfection and was not affected by PEI/LV particles (not shown). Occludin localization was not altered by incubation of cells with $\mathrm{PEI} / \mathrm{LV}$ at 24 hours (Figures $7(\mathrm{~b})-7(\mathrm{~d})$ ). Also free PEI $\left(10^{7}\right.$ molecules) did not exert any effect on TJ integrity (Figure 7(e)).

\section{Discussion}

Positively charged polycations such as polybrene are known to be required for efficient infection of cells with retroviruses and retrovirus vectors, possibly by stabilizing the interaction between negatively charged virus particles and target cellular membranes [20, 39]. Indeed, polybrene has been used also in LV-mediated transduction of polarized epithelial cells obtained from the airways [40]. In our hands, polybrene was toxic to the cells and thus it was withdrawn from the transduction protocol. For this reason, we had to use high MOIs (i.e. at least 2000) to achieve a meaningful transduction of polarized airway bronchial and tracheal epithelial cells [21]. In this study, we show that high LV MOIs are toxic to polarized airway epithelial cells, which are considered a good approximative model for native airway epithelium [26, 41-43]. High MOIs determined an increase in membrane permeability at 24 hours but not at 4 hours, suggesting that the direct interaction of LV particles with cells is not harmful, rather it is so for entry, transport, and viral transcription within the cytosol. Interestingly, the damage caused by LV particles was reflected also by the decrease of TER and loss of occludin at the TJs between cells. The MTT assay shows that only high LV doses decreased the cellular viability both at 4 and 24 hours. However, this was a small decrease as compared with the pemeabilizing effect. These results strongly suggest that LV particles exert their toxic action through direct interaction with TJ proteins, an effect visible only at 24 hours. Some recently acquired data indicate that proficient viral infection is dependent on the interaction of viral envelope glycoproteins with TJ proteins. The primary CVB receptor, the coxsackievirus and adenovirus receptor (CAR), is a transmembrane component of the TJ [44] and
CVB enters polarized epithelial cells from the TJ, causing a transient disruption of TJ integrity [45]. CVB does not induce major reorganization of the TJ, but stimulates the specific internalization of occludin within macropinosomes [29]. HCV envelope glycoproteins induce a loss of claudin$1, \mathrm{ZO}-1$, and occludin-delineated junctional accumulation [30] and occludin is required for late entry step of $\mathrm{HCV}$ into cells [46]. Overall, based on our previous publication [21], we speculate that VSV-G-pseudotyped LV virions are concentrated on the apical surface of polarized airway epithelial cells by initial attachment to GAGs. The binding of LV particles with GAGs is based on nonelectrostatic interactions [20]. In a further step, LV virions should then bind to entry receptors (not identified yet) and eventually to occludin for internalization.

Loss of occludin from the TJs and their opening could be a disadvantage in lung diseases such as CF, because of the presence of bacteria and bacterial products in the airways. In order to find a transduction protocol with less viral loads, minimal toxicity and eventually no delocalization of occludin from the TJs, we have combined LV particles with the polycation PEI, based on the rationale that a cationic component would charge associate with LV particles, which carry a net negative surface charge. Several previous studies have reported the use of cationic molecules to enhance viral uptake and subsequent transgene expression in vitro and in vivo, mainly for adenoviral [47-52] and retroviral vectors [33-36]. In particular, PEI facilitated transduction efficiency by adenoviral vectors in cultured mouse myotubes [47] and in 9L gliosarcoma cells [49] and enhanced retroviral transduction in NIH3T3 cells [36]. To our best knowledge, ours is the first study showing that PEI enhanced LVmediated transduction of airway epithelial cells. PEI/LV particles increased membrane permeability only at the highest PEI/LV ratio, an effect likely due to excess free PEI [53], with a little effect on the viability. Indeed, PEI is known to induce the formation of transient, nanoscale holes in the membranes of living cells and these holes allow a greatly enhanced exchange of materials across the cell membrane, including propidium iodide [54]. Although we have not investigated the membrane permeability with spermidine/LV vectors, the fact that spermidine had no enhancing effect on LV-mediated transduction supports the notion that the PEI's action is due to a membrane destabilizing effect. PEI/LV particles and free PEI did not cause any alteration on TER and in occludin localization, indicating that PEI-induced nanoscale holes in the plasma membrane do not affect TJ integrity.

In conclusion, $\mathrm{PEI} / \mathrm{LV}$ vectors are more efficient than LV alone-used at low viral load-in transducing polarized epithelial cells without so pronounced cytotoxicity, and, more importantly, without disrupting tight junctions. Because the transduction efficiency mediated by PEI/LV is still low it needs further refinement for obtaining higher transduction rates of polarized airway epithelia, a goal which could be achieved by testing other PEI architectures [55]. For these reasons the PEI/LV vector warrants further characterization for being considered as a valid tool in gene therapy of genetic lung diseases. 


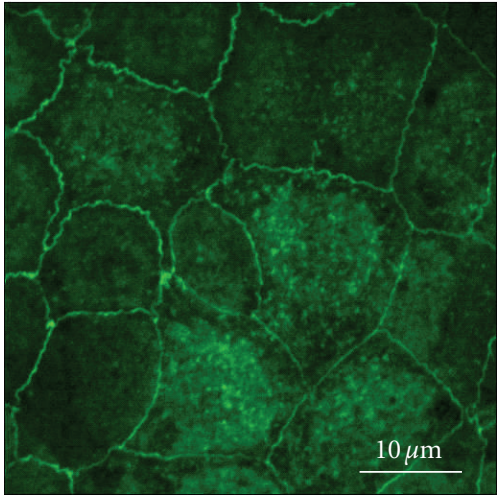

(a)

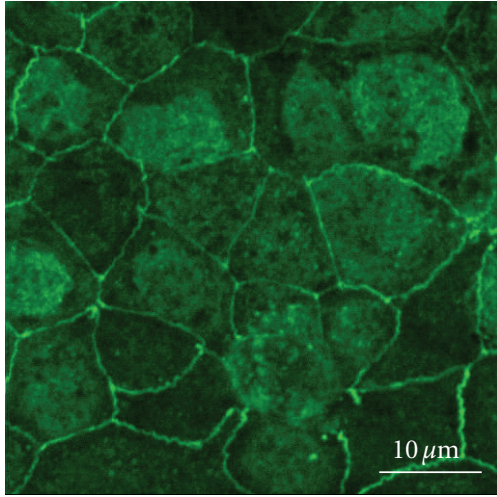

(b)

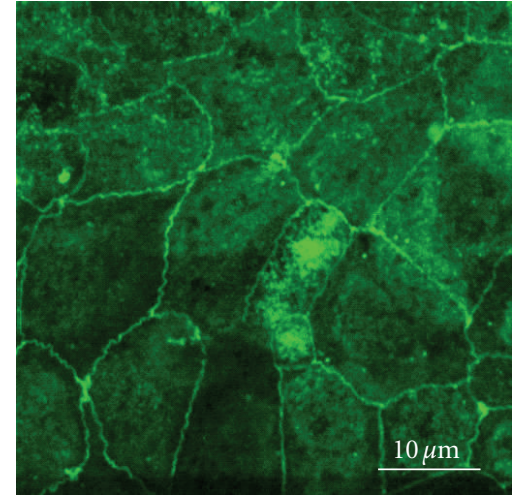

(c)

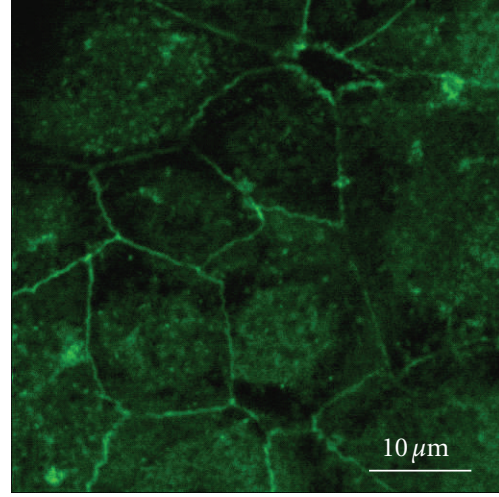

(d)

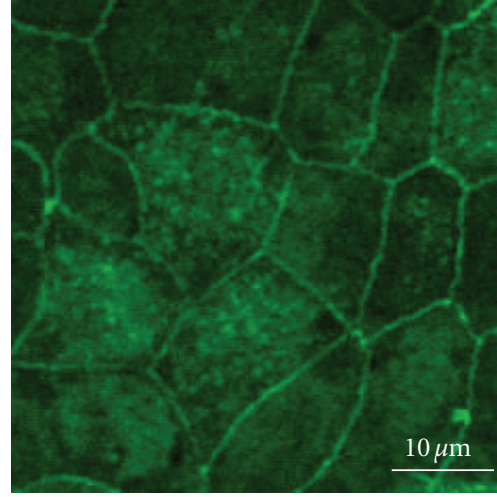

(e)

Figure 7: Effect of PEI/LV vectors and free PEI on occludin localization. Polarized $16 \mathrm{HBE} 41$ - cells were incubated with free $1 \times 10^{7}$ PEI molecules (e) or PEI/LV vectors formulated at ratios of $5 \times 10^{4}$ (b), $1 \times 10^{6}$ (c), and $1 \times 10^{7}$ (d) with 50 MOI LV for 24 hours and then evaluated for occludin localization by confocal microscopy. Mock (a) is represented by cells incubated with medium only. Note in green the circumferential localization of occludin between cells, with some intracellular staining. En-face micrographs are shown. Bar: $10 \mu \mathrm{m}$.

\section{Acknowledgments}

The authors are grateful to Professor L. Naldini who has generously provided LV plasmids and to Professor D. Gruenert for 16HBE41o- cells. This work was supported by the European Commission Grant LSHB-CT-2004-005213 and Fondazione Banca del Monte Domenico SiniscalcoCeci.

\section{References}

[1] E. Copreni, M. Penzo, S. Carrabino, and M. Conese, "Lentivirus-mediated gene transfer to the respiratory epithelium: a promising approach to gene therapy of cystic fibrosis," Gene Therapy, vol. 11, no. 1, pp. S67-S75, 2004.

[2] M. Conese, E. Copreni, D. Piro, and J. Rejman, "Gene and cell therapy for the treatment of cystic fibrosis," Advances in Gene, Molecular and Cell Therapy, vol. 1, pp. 99-119, 2007.

[3] P. L. Sinn, E. R. Burnight, M. A. Hickey, G. W. Blissard, and P. B. McCray Jr., "Persistent gene expression in mouse nasal epithelia following feline immunodeficiency virus-based vector gene transfer," Journal of Virology, vol. 79, no. 20, pp. 12818-12827, 2005.
[4] G. Wang, V. Slepushkin, J. Zabner et al., "Feline immunodeficiency virus vectors persistently transduce nondividing airway epithelia and correct the cystic fibrosis defect," Journal of Clinical Investigation, vol. 104, no. 11, pp. R55-R62, 1999.

[5] M. Limberis, D. S. Anson, M. Fuller, and D. W. Parsons, "Recovery of airway cystic fibrosis transmembrane conductance regulator function in mice with cystic fibrosis after single-dose lentivirus-mediated gene transfer," Human Gene Therapy, vol. 13, no. 16, pp. 1961-1970, 2002.

[6] K. L. Kremer, K. R. Dunning, D. W. Parsons, and D. S. Anson, "Gene delivery to airway epithelial cells in vivo: a direct comparison of apical and basolateral transduction strategies using pseudotyped lentivirus vectors," Journal of Gene Medicine, vol. 9, no. 5, pp. 362-368, 2007.

[7] F.-Y. Lim, G. P. Kobinger, D. J. Weiner, A. Radu, J. M. Wilson, and T. M. Crombleholme, "Human fetal tracheascid mouse xenografts: efficacy of vesicular stomatitis virusG pseudotyped lentiviral-mediated gene transfer," Journal of Pediatric Surgery, vol. 38, no. 6, pp. 834-839, 2003.

[8] P. L. Sinn, A. C. Arias, K. A. Brogden, and P. B. McCray Jr., "Lentivirus vector can be readministered to nasal epithelia without blocking immune responses," Journal of Virology, vol. 82, no. 21, pp. 10684-10692, 2008. 
[9] E. Copreni, E. Nicolis, A. Tamanini et al., "Late generation lentiviral vectors: evaluation of inflammatory potential in human airway epithelial cells," Virus Research, vol. 144, no. 12, pp. 8-17, 2009.

[10] G. P. Kobinger, D. J. Weiner, Q.-C. Yu, and J. M. Wilson, "Filovirus-pseudotyped lentiviral vector can efficiently and stably transduce airway epithelia in vivo," Nature Biotechnology, vol. 19, no. 3, pp. 225-230, 2001.

[11] R. J. Pickles, D. McCarty, H. Matsui, P. J. Hart, S. H. Randell, and R. C. Boucher, "Limited entry of adenovirus vectors into well-differentiated airway epithelium is responsible for inefficient gene transfer," Journal of Virology, vol. 72, no. 7, pp. 6014-6023, 1998.

[12] R. W. Walters, T. Grunst, J. M. Bergelson, R. W. Finberg, M. J. Welsh, and J. Zabner, "Basolateral localization of fiber receptors limits adenovirus infection from the apical surface of airway epithelia," The Journal of Biological Chemistry, vol. 274, no. 15, pp. 10219-10226, 1999.

[13] J. Zabner, P. Freimuth, A. Puga, A. Fabrega, and M. J. Welsh, "Lack of high affinity fiber receptor activity explains the resistance of ciliated airway epithelia to adenovirus infection," Journal of Clinical Investigation, vol. 100, no. 5, pp. 1144-1149, 1997.

[14] C. Summerford, J. S. Bartlett, and R. J. Samulski, “ $\alpha \mathrm{V} \beta 5$ integrin: a co-receptor for adeno-associated virus type 2 infection," Nature Medicine, vol. 5, no. 1, pp. 78-82, 1999.

[15] C. Summerford and R. J. Samulski, "Membrane-associated heparan sulfate proteoglycan is a receptor for adenoassociated virus type 2 virions," Journal of Virology, vol. 72, no. 2, pp. 1438-1445, 1998.

[16] M. P. Boyle, R. A. Enke, J. B. Reynolds, P. J. Mogayzel Jr., W. B. Guggino, and P. L. Zeitlin, "Membrane-associated heparan sulfate is not required for rAAV-2 infection of human respiratory epithelia," Virology Journal, vol. 3, p. 29, 2006.

[17] D. Duan, Y. Yue, Z. Yan, P. B. Mccray Jr., and J. F. Engelhardt, "Polarity influences the efficiency of recombinant adenoassociated virus infection in differentiated airway epithelia," Human Gene Therapy, vol. 9, no. 18, pp. 2761-2776, 1998.

[18] G. Wang, B. L. Davidson, P. Melchert et al., "Influence of cell polarity on retrovirus-mediated gene transfer to differentiated human airway epithelia," Journal of Virology, vol. 72, no. 12, pp. 9818-9826, 1998.

[19] L. G. Johnson, J. C. Olsen, L. Naldini, and R. C. Boucher, "Pseudotyped human lentiviral vector-mediated gene transfer to airway epithelia in vivo," Gene Therapy, vol. 7, no. 7, pp. 568-574, 2000.

[20] G. H. Guibinga, A. Miyanohara, J. D. Esko, and T. Friedmann, "Cell surface heparan sulfate is a receptor for attachment of envelope protein-free retrovirus-like particles and VSV-G pseudotyped MLV-derived retrovirus vectors to target cells," Molecular Therapy, vol. 5, no. 5, pp. 538-546, 2002.

[21] E. Copreni, S. Castellani, L. Palmieri, M. Penzo, and M. Conese, "Involvement of glycosaminoglycans in vesicular stomatitis virus $\mathrm{G}$ glycoprotein pseudotyped lentiviral vectormediated gene transfer into airway epithelial cells," Journal of Gene Medicine, vol. 10, no. 12, pp. 1294-1302, 2008.

[22] A. Follenzi, L. E. Ailles, S. Bakovic, M. Geuna, and L. Naldini, "Gene transfer by lentiviral vectors is limited by nuclear translocation and rescued by HIV-1 pol sequences," Nature Genetics, vol. 25, no. 2, pp. 217-222, 2000.

[23] M. A. King, "Detection of dead cells and measurement of cell killing by flow cytometry," Journal of Immunological Methods, vol. 243, no. 1-2, pp. 155-166, 2000.
[24] J. A. Steinkamp, B. E. Lehnert, and N. M. Lehnert, "Discrimination of damaged/dead cells by propidium iodide uptake in immunofluorescently labeled populations analyzed by phasesensitive flow cytometry," Journal of Immunological Methods, vol. 226, no. 1-2, pp. 59-70, 1999.

[25] M. Conese, P. Montemurro, R. Fumarulo, D. Giordano, S. Riccardi, and M. N. Colucci Semeraro, "Inhibitory effect of retinoids on the generation of procoagulant activity by blood mononuclear phagocytes," Thrombosis and Haemostasis, vol. 66, no. 6, pp. 662-665, 1991.

[26] J. Rejman, S. Di Gioia, A. Bragonzi, and M. Conese, "Pseudomonas aeruginosa infection destroys the barrier function of lung epithelium and enhances polyplex-mediated transfection," Human Gene Therapy, vol. 18, no. 7, pp. 642-652, 2007.

[27] L. González-Mariscal, A. Betanzos, P. Nava, and B. E. Jaramillo, "Tight junction proteins," Progress in Biophysics and Molecular Biology, vol. 81, no. 1, pp. 1-44, 2003.

[28] E. E. Schneeberger and R. D. Lynch, "The tight junction: a multifunctional complex," American Journal of Physiology, vol. 286, no. 6, pp. C1213-C1228, 2004.

[29] C. B. Coyne, L. Shen, J. R. Turner, and J. M. Bergelson, "Coxsackievirus entry across epithelial tight junctions requires occludin and the small GTPases Rab34 and Rab5," Cell Host and Microbe, vol. 2, no. 3, pp. 181-192, 2007.

[30] I. Benedicto, F. Molina-Jiménez, O. Barreiro et al., "Hepatitis $\mathrm{C}$ virus envelope components alter localization of hepatocyte tight junction-associated proteins and promote occludin retention in the endoplasmic reticulum," Hepatology, vol. 48, no. 4, pp. 1044-1053, 2008.

[31] J. S. Alexander, T. Dayton, C. Davis et al., "Activated Tlymphocytes express occludin, a component of tight junctions," Inflammation, vol. 22, no. 6, pp. 573-582, 1998.

[32] M. S. Smith, G. L. Bentz, J. S. Alexander, and A. D. Yurochko, "Human cytomegalovirus induces monocyte differentiation and migration as a strategy for dissemination and persistence," Journal of Virology, vol. 78, no. 9, pp. 4444-4453, 2004.

[33] C. P. Hodgson and F. Solaiman, "Virosomes: cationic liposomes enhance retroviral transduction," Nature Biotechnology, vol. 14, no. 3, pp. 339-342, 1996.

[34] W. P. Swaney, F. L. Sorgi, A. B. Bahnson, and J. A. Barranger, "The effect of cationic liposome pretreatment and cenfrifugation on retrovirus-mediated gene transfer," Gene Therapy, vol. 4, no. 12, pp. 1379-1386, 1997.

[35] C. D. Porter, K. V. Lukacs, G. Box, Y. Takeuchi, and M. K. L. Collins, "Cationic liposomes enhance the rate of transduction by a recombinant retroviral vector in vitro and in vivo," Journal of Virology, vol. 72, no. 6, pp. 4832-4840, 1998.

[36] M. Themis, S. J. Forbes, L. Chan et al., "Enhanced in vitro and in vivo gene delivery using cationic agent complexed retrovirus vectors," Gene Therapy, vol. 5, no. 9, pp. 1180-1186, 1998.

[37] I. S. Blagbrough, A. J. Geall, and A. P. Neal, "Polyamines and novel polyamine conjugates interact with DNA in ways that can be exploited in non-viral gene therapy," Biochemical Society Transactions, vol. 31, no. 2, pp. 397-406, 2003.

[38] D. Fischer, T. Bieber, Y. Li, H.-P. Elsässer, and T. Kissel, "A novel non-viral vector for DNA delivery based on low molecular weight, branched polyethylenimine: effect of molecular weight on transfection efficiency and cytotoxicity," Pharmaceutical Research, vol. 16, no. 8, pp. 1273-1279, 1999.

[39] K. S. Rostand and J. D. Esko, "Microbial adherence to and invasion through proteoglycans," Infection and Immunity, vol. 65 , no. 1 , pp. 1-8, 1997. 
[40] Z. Borok, J. E. Harboe-Schmidt, S. L. Brody et al., "Vesicular stomatitis virus G-pseudotyped lentivirus vectors mediate efficient apical transduction of polarized quiescent primary alveolar epithelial cells," Journal of Virology, vol. 75, no. 23, pp. 11747-11754, 2001.

[41] A. L. Cozens, M. J. Yezzi, K. Kunzelmann et al., "CFTR expression and chloride secretion in polarized immortal human bronchial epithelial cells," American Journal of Respiratory Cell and Molecular Biology, vol. 10, no. 1, pp. 38-47, 1994.

[42] P. J. Mohler, S. M. Kreda, R. C. Boucher, M. Sudol, M. J. Stutts, and S. L. Milgram, "Yes-associated protein 65 localizes p62(c-Yes) to the apical compartment of airway epithelia by association with EBP50," Journal of Cell Biology, vol. 147, no. 4, pp. 879-890, 1999.

[43] L. Guerra, T. Fanelli, M. Favia et al., "Na+/H+ exchanger regulatory factor isoform 1 overexpression modulates cystic fibrosis transmembrane conductance regulator (CFTR) expression and activity in human airway 16HBE14o- cells and rescues $\triangle \mathrm{F} 508$ CFTR functional expression in cystic fibrosis cells," The Journal of Biological Chemistry, vol. 280, no. 49, pp. 40925-40933, 2005.

[44] C. J. Cohen, J. T. C. Shieh, R. J. Pickles, T. Okegawa, J.T. Hsieh, and J. M. Bergelson, "The coxsackievirus and adenovirus receptor is a transmembrane component of the tight junction," Proceedings of the National Academy of Sciences of the United States of America, vol. 98, no. 26, pp. 1519115196, 2001.

[45] C. B. Coyne and J. M. Bergelson, "Virus-induced Abl and Fyn kinase signals permit coxsackievirus entry through epithelial tight junctions," Cell, vol. 124, no. 1, pp. 119-131, 2006.

[46] I. Benedicto, F. Molina-Jiménez, B. Bartosch et al., "The tight junction-associated protein occludin is required for a postbinding step in hepatitis C virus entry and infection," Journal of Virology, vol. 83, no. 16, pp. 8012-8020, 2009.

[47] E. Dodds, T. A. Piper, S. J. Murphy, and G. Dickson, "Cationic lipids and polymers are able to enhance adenoviral infection of cultured mouse myotubes," Journal of Neurochemistry, vol. 72, no. 5, pp. 2105-2112, 1999.

[48] S. M. Arcasoy, J. D. Latoche, M. Gondor, B. R. Pitt, and J. M. Pilewski, "Polycations increase the efficiency of adenovirusmediated gene transfer to epithelial and endothelial cells in vitro," Gene Therapy, vol. 4, no. 1, pp. 32-38, 1997.

[49] A. Fasbender, J. Zabner, M. Chillón et al., "Complexes of adenovirus with polycationic polymers and cationic lipids increase the efficiency of gene transfer in vitro and in vivo," The Journal of Biological Chemistry, vol. 272, no. 10, pp. 64796489, 1997.

[50] M. Chillón, J. H. Lee, A. Fasbender, and M. J. Welsh, "Adenovirus complexed with polyethylene glycol and cationic lipid is shielded from neutralizing antibodies in vitro," Gene Therapy, vol. 5, no. 7, pp. 995-1002, 1998.

[51] J. M. Kaplan, S. E. Pennington, J. A. St. George et al., "Potentiation of gene transfer to the mouse lung by complexes of adenovirus vector and polycations improves therapeutic potential," Human Gene Therapy, vol. 9, no. 10, pp. 14691479, 1998.

[52] C. Qiu, M. B. De Young, A. Finn, and D. A. Dichek, "Cationic liposomes enhance adenovirus entry via a pathway independent of the fiber receptor and $\alpha(\mathrm{v})$-integrins," Human Gene Therapy, vol. 9, no. 4, pp. 507-520, 1998.

[53] D. Finsinger, J.-S. Remy, P. Erbacher, C. Koch, and C. Plank, "Protective copolymers for nonviral gene vectors: synthesis, vector characterization and application in gene delivery," Gene Therapy, vol. 7, no. 14, pp. 1183-1192, 2000.
[54] S. Hong, P. R. Leroueil, E. K. Janus et al., "Interaction of polycationic polymers with supported lipid bilayers and cells: nanoscale hole formation and enhanced membrane permeability," Bioconjugate Chemistry, vol. 17, no. 3, pp. 728734, 2006.

[55] S. Di Gioia and M. Conese, "Polyethylenimine-mediated gene delivery to the lung and therapeutic applications," Journal of Drug Design, Development and Therapy, vol. 2, pp. 163-188, 2008. 

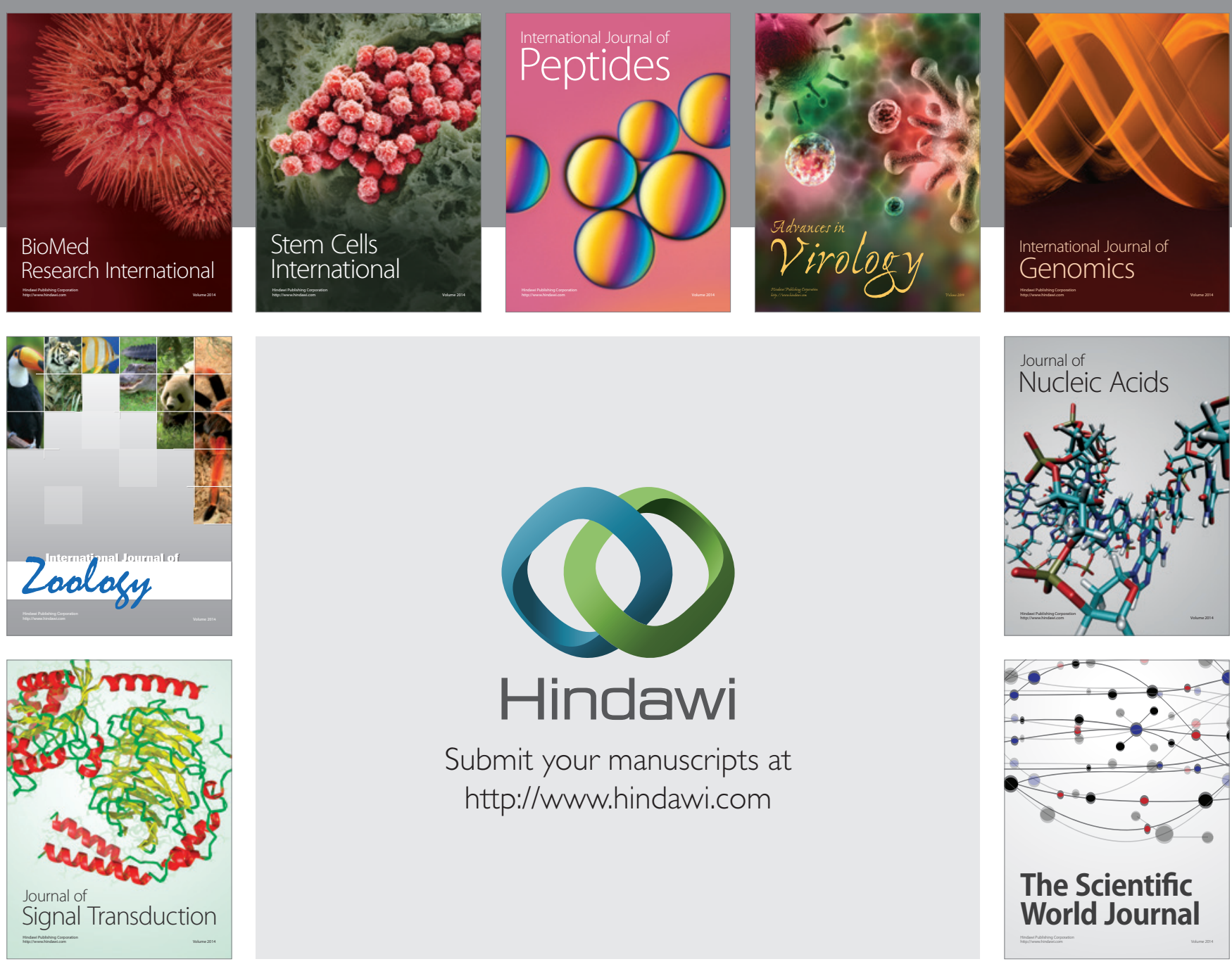

Submit your manuscripts at

http://www.hindawi.com
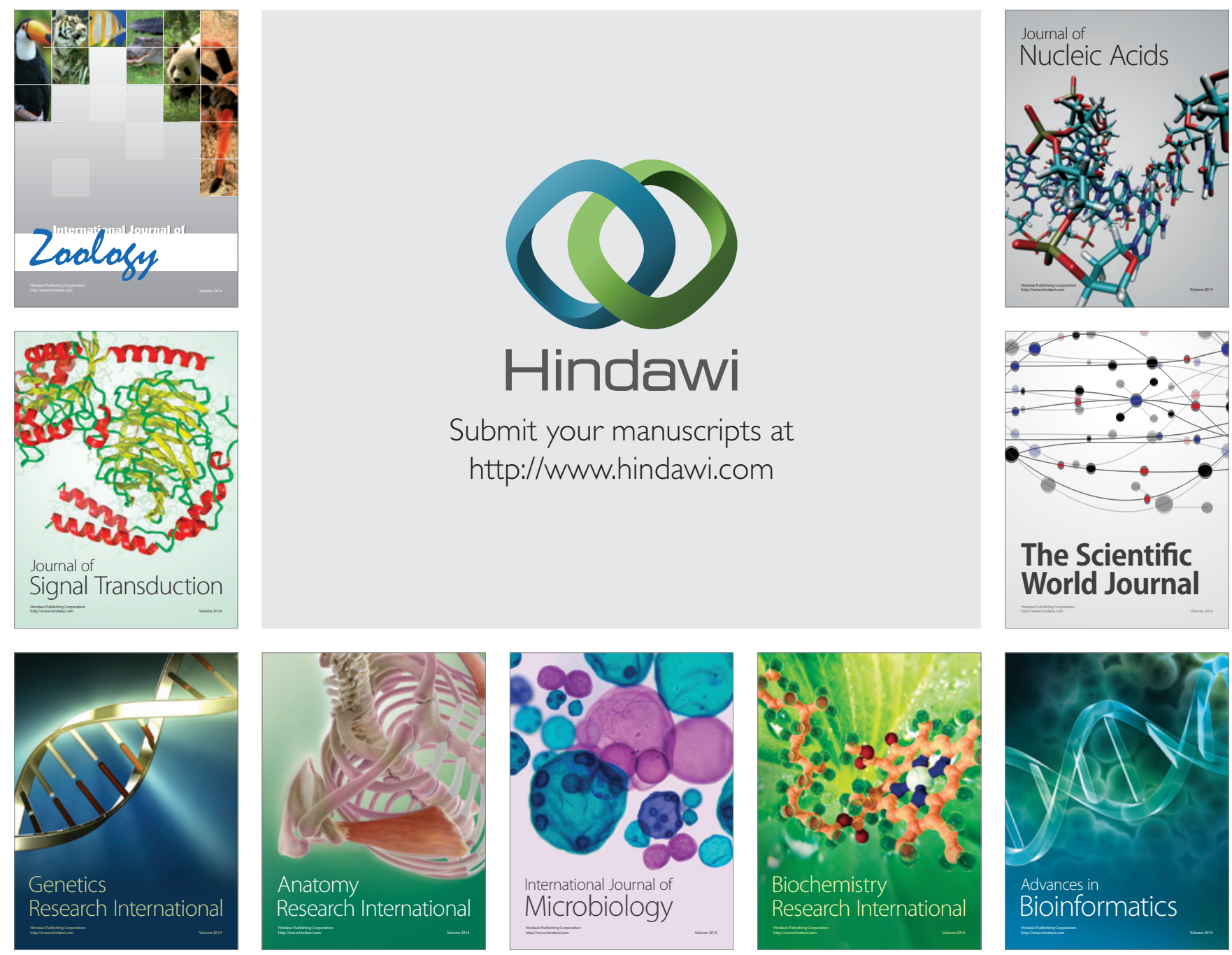

The Scientific World Journal
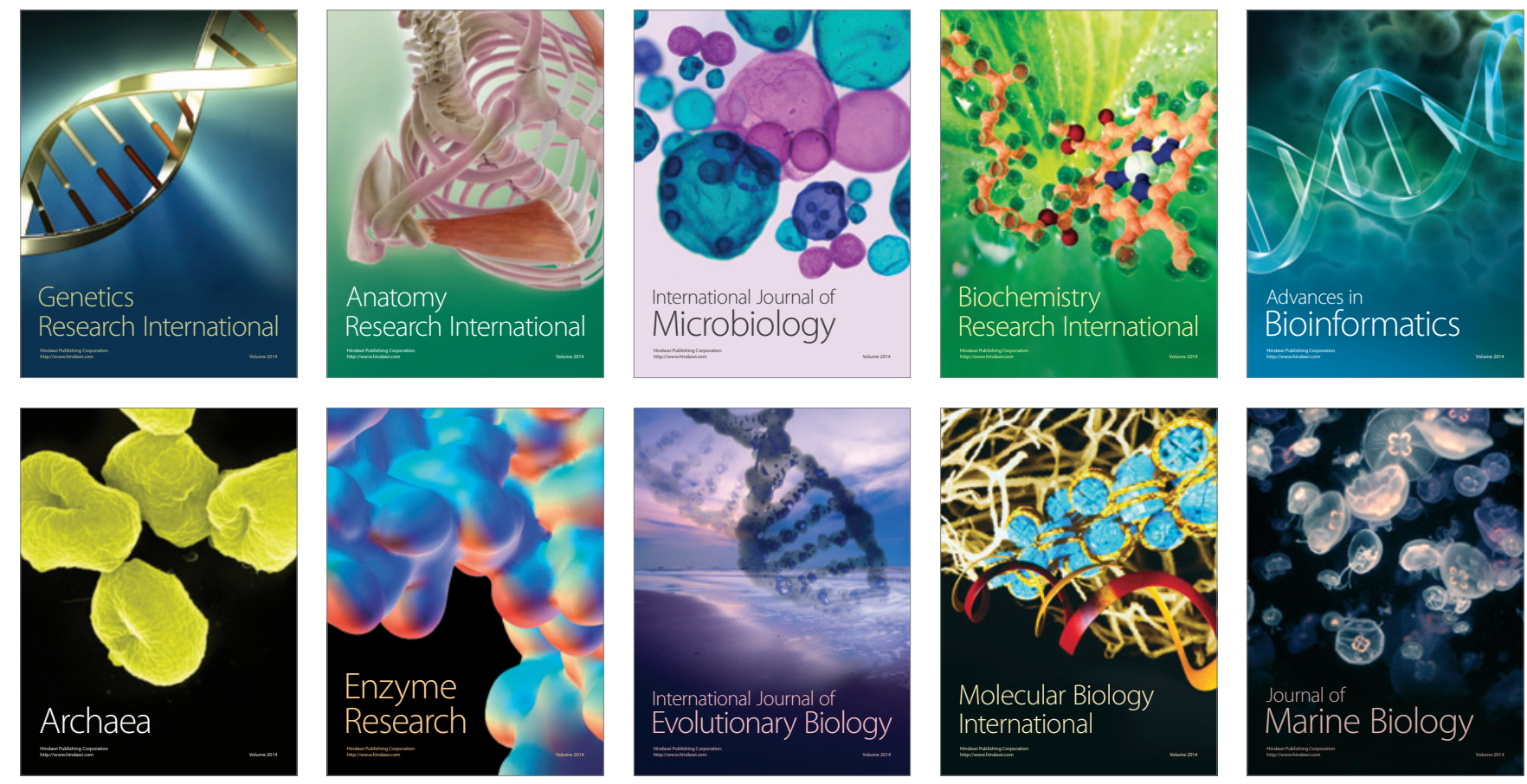